\title{
Automated Proton Titrations of Pancreatic Phospholipase $\mathrm{A}_{2}{ }^{1}$
}

\author{
Gabriëlle M. Donné-Op den Kelder, Gerard H. de HaAs, \\ AND MAARTEN R. EGMOND \\ Laboratory of Biochemistry, State University of Utrecht, Transitorium III, Padualaan 8, \\ NL-3584 CH Utrecht, The Netherlands \\ Received March 10, 1982
}

\begin{abstract}
A computer-controlled titration system has been developed, tested, and used for analysis of the proton-titration behavior of pancreatic phospholipase $A_{2}$ from ox, horse, and pig. The results revealed an error in the reported amino acid composition of the equine enzyme. A simple interface for the input of digitized data from a $\mathrm{pH}$ meter is described together with the software developed for controlling the titration experiments.
\end{abstract}

The development of an automatic protontitration system has become a very important tool in performing fast and accurate experiments. The ability of adding accurately very small amounts of titrant (1 $\pm 0.075 \mu \mathrm{l})$ renders it possible to work at relatively low enzyme concentrations (approximately $0.2 \%$ ). In one titration experiment a broad $\mathrm{pH}$ range can be covered (e.g., pH 3-11), while relatively small amounts of titrant need to be added (about 300 to 400 $\mu$ l titrant, titer $0.064 \mathrm{M}$ ).

In this paper we describe a simple interface connecting a microprocessor, $\mathrm{pH}$ meter, and a titrator. By means of test experiments we demonstrate the accuracy and reproducibility of the titration system and analyze the titration behavior of pancreatic $\mathrm{PLA}_{2}{ }^{2}$ from horse, ox, and pig.

\section{EXPERIMENTAL}

Materials and methods. The pancreatic prophospholipases $\mathrm{A}_{2}$ from pig, horse, and

${ }^{1}$ This study was partly carried out under the auspices of the Netherlands Foundation of Chemical Research (SON) and with financial aid from the Netherlands Organization for the Advancement of Pure Research (ZWO).

${ }^{2}$ Abbreviations used: PLA, phospholipase $\mathrm{A}_{2}$; IIP, isoionic $\mathrm{pH}$; LSD, least significant digit; $\mathrm{I} / \mathrm{O}$, input/ output. ox were purified from pancreatic tissue and converted into phospholipases $\mathrm{A}_{2}$ by limited proteolysis as described by Nieuwenhuizen et al. (1), Evenberg et al. (2), and Fleer $e t$ al. (3), respectively. Protein concentrations were calculated from the absorbance at 280 $\mathrm{nm}$ using $E_{1 \mathrm{~cm}}^{1 \%}$ values of 12.3 for bovine and equine $\mathrm{PLA}_{2}$ and a value of 13.0 for porcine $\mathrm{PLA}_{2}$.

The enzyme was dissolved in distilled degassed water. Subsequently, it was deionized by passing it through a mixed-bed ion-exchange column $(1 \times 10 \mathrm{~cm})$ in a closed system free from $\mathrm{CO}_{2}$. The ion-exchange material consisted of IR 400 anion-exchange resin and IR 120 cation-exchange resin mixed together according to their relative capacities (2:1, respectively). The protein solution (3-4 ml) placed on the column usually contained about $0.6 \%$ protein, and recycling was performed until a stable conductivity of about 1 to $2 \mu$ mho was reached. Collection of the protein from the column generally resulted in about $17 \mathrm{ml}$ of $0.2 \%$ protein. The protein concentration was measured spectrophotometrically at $280 \mathrm{~nm}$.

Titration procedure. The $\mathrm{pH}$ meter equipped with a combined calomel electrode was calibrated with standard $0.05 \mathrm{M}$ phtalate (Radiometer S1316) and $0.05 \mathrm{M}$ phosphate 


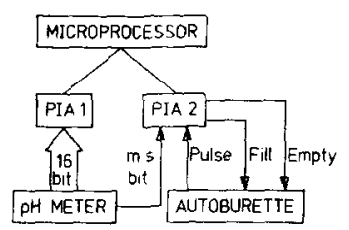

FIG. 1. Schematic representation of the interface design connecting $\mathrm{pH}$ metcr, titrator, and microprocessor. PIA1 and PIA2, peripheral interface adapters, are 16bit $1 / O$ programmable devices; $m s$, most significant.

(S1326) buffers. The isoionic $\mathrm{pH}$ (IIP) was measured for a fresh protein solution $(5 \mathrm{ml})$. The solution was brought to the required ionic strength (usually $I=0.1 \mathrm{M}$ ) by adding solid $\mathrm{KCl}$ (Merck, grade purity). The stirred solution was kept at $25.0 \pm 0.2^{\circ} \mathrm{C}$ and was held continuously under a nitrogen atmosphere. The nitrogen gas was passed over solid $\mathrm{KOH}$ and then wetted by bubbling through $\mathrm{CO}_{2}$-free distilled water. Generally, titrations were carried out using $\mathrm{CO}_{2}$-free $0.0643 \mathrm{M} \mathrm{NaOH}$ (Titrisol, Merck) starting at $\mathrm{pH} 3$ and titrating until $\mathrm{pH} 10-11$. During the proton titration a maximum of 500 data points was generated. Each point represents a pH value, the proton charge of the protein molecule at that $\mathrm{pH}$ value, the derivative of the titration curve in that point, and the amount of added titrant. After the experiment, these data are stored together with the values of the initial volume, enzyme concentration, titer, and number of data points. The experiments were repeated at least twice and data were averaged and stored on diskettes for further analysis.

Titration equipment. A Radiometer titration system comprising a PHM64 research pH meter, a GK2321 C combined electrode, an ABU80 Autoburette, and a TTA60 titration assembly (stand, electrode holder, and stirrer) was used. Accuracies of additions of titrant are $0.5 \mu \mathrm{l}$ for titrator mode $1 / 1$ ( $1 / 2$ of LSD on display) and $0.075 \mu 1$ for mode $1 / 10$ ( $1 / 2$ of LSD on display $+0.01 \%$ of full burette volume).

Hardware. In general, any microcomputer of the Rockwell R6500 type can be used.
The microprocessor used here is an Apple II Europlus computer (Apple Computer) with 48 kilobytes RAM and a Disk II floppy disk subsystem with two minifloppy disk drives with 116 kilobytes of storage capacity per disk. A Centronics printer (Data Computer) and a Hewlett-Packard Model 7225A plotter provide communications and reporting facilities.

Programming language. Most of the software was written in Apple II BASIC language. However, some software routines for the interfaces were written in machine language (assembler) to enhance the information exchange rate between microprocessor and peripheral accessories (e.g., plotter, autoburette).

Interface design. In the automatic titration system the microprocessor is interfaced to the autoburette and the digital $\mathrm{pH}$ meter (Fig. 1). The $\mathrm{pH}$ is read to an accuracy of $0.001 \mathrm{pH}$ unit, digitized, and converted into a 5-digit BCD number. Four BCD digits are fed to the microprocessor via 16-data input lines on a 16-bit peripheral interface adapter (Motorola M6821) indicated as PIA1 in Fig. 1. Only 1 extra bit is required for the remaining (most significant) BCD digit (i.e., 0 for $\mathrm{pH}$ values below 10 and 1 for $\mathrm{pH}$ values from 10 and above). This extra bit is fed to the computer via a second interface adapter, PIA2. The I/O connections to the titrator unit are completed by three lines, one input line to count the number of revolutions of the titrator motor ( 1 pulse output/revolution) and two output lines to activate the titrator motor itself (full and empty burette command). An assembly language routine is written to activate the titrator, to count the number of revolutions of the motor, and to stop the addition of titrant when the end value is reached. This simple routine (program COUNTER) avoids the extra cost in case a hardware counting system is incorporated.

Titration-controlling program. After initializing the interfaces and loading program COUNTER, program TITRATE (see flow 
diagram in Fig. 2) asks for input which is essential for the control of the titration and for the calculation of $\bar{Z}_{\mathrm{H}}$, i.e., the proton charge of the protein molecule determined from the number of protons added or subtracted per protein molecule. The titrator mode $(1 / 1$ or $1 / 10)$ indicates the number of revolutions of the titrator motor necessary for addition of $1 \mu \mathrm{l}$ of titrant, i.e., 1 revolution in mode $1 / 1$ and 10 in mode $1 / 10$. With the given data the number of cycles can be calculated for the addition of volume $Q(\mu 1)$. Subsequently, $\mathrm{pH}$ values are read at fixed-time intervals of about $1 \mathrm{~s}$ until constant values are obtained within operatordefined limits. After every addition the $\mathrm{pH}$, $\bar{Z}_{\mathrm{H}}, \mathrm{dpH} / \mathrm{d} \bar{Z}_{\mathrm{H}}$, and added volume are displayed on a monitor (Philips, TY 007062).

Procedure of analysis. The analyses of the titration curves are performed according to the method developed by Linderstrøm-Lang (4) and described by Tanford (5) using the relation

$$
\mathrm{pH}-\log \frac{\alpha_{i}}{1-\alpha_{i}}=\mathrm{p} K_{\mathrm{int}}^{(i)}-0.868 w \bar{Z}
$$

where $\alpha_{i}$ is the average degree of dissociation of a titratable group $i$ and $K_{\text {int }}^{(i)}$ the intrinsic dissociation constant for that group (i.e., $K_{i}$ in the absence of long-range electrostatic interactions). $\bar{Z}$ is the net charge of the protein and $w$ the electrostatic interaction factor depending on size and shape of the molecule and on the type of solvent (dielectric constant, ionic strength). In all calculations $w$ was assumed to be constant over the whole titration range and $\bar{Z}$ was replaced by $\bar{Z}_{\mathrm{H}}$, the averaged charge of the protein due to binding of protons only. For $\bar{Z}_{\mathbf{H}}$ we can write the relation

$$
\bar{Z}_{\mathrm{H}}=Z_{\max }-\sum n_{i} \alpha_{i}
$$

where $Z_{\max }$ is the maximum positive proton charge being equal to the sum of the number of titratable histidines, arginines, lysines, and terminal amino groups.

For the derivative of the titration curve

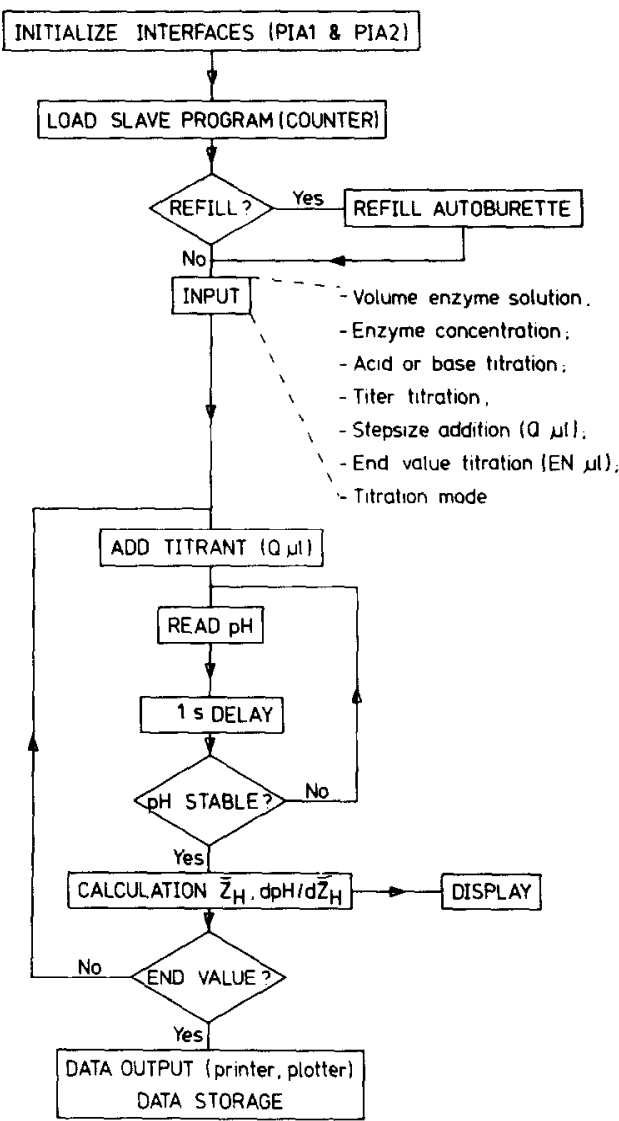

FIG. 2. Flow diagram of the titration-controlling program TITRATE written for the most part in BASIC.

we have the relation

$$
\begin{array}{r}
-\mathrm{dpH} / \mathrm{d} \bar{Z}_{\mathbf{H}}=1 /\left[2.303 \sum n_{i} \alpha_{i}\left(1-\alpha_{i}\right)\right] \\
+0.868 w
\end{array}
$$

with $n_{i}$ the number of groups titrating in class $i$ and assuming $w$ to be constant during the experiment (for an exact deduction see Ref. (6)). The results will be presented as normal titration curves ( $\mathrm{pH}$ vs $\bar{Z}_{\mathrm{H}}$ ) and differential titration curves $\left(-\mathrm{dpH} / \mathrm{d} \bar{Z}_{\mathrm{H}}\right.$ vs $\left.\bar{Z}_{\mathrm{H}}\right)$. The latter usually shows two peaks, one near pH 5.5-6 and a second near pH 8-9. The maxima represent "points of minimum titration," i.e., points in which $\alpha$ of all titratable groups is 1 or 0 . This allows the accurate determination of the number of amino acids in one group, given a sharp de- 


\section{TABLE}

Partial amino acid Cumpusition and ELECTROSTATIC INTERACTION FACTOR $w^{a}$ FOR Porcine, Bovine, AND EQUine PL $/ A_{2}{ }^{b}$

\begin{tabular}{lccc}
\hline \multicolumn{1}{c}{ Nature of groups } & Porcine & Bovine & Equine \\
\cline { 2 - 4 }$\alpha$-COOH & 1 & 1 & 1 \\
Aspartic acid & 9 & 9 & 8 \\
Glutamic acid & 6 & 5 & 7 \\
Histidine & 3 & 2 & 1 \\
$\alpha$-Amino & 1 & 1 & 1 \\
Lysine & 9 & 11 & 8 \\
Tyrosine & 8 & 7 & 7 \\
Arginine & 4 & 2 & 4 \\
$w(200 \mathrm{mM} \mathrm{KCl}) \times 10^{-3}$ & 87.4 & 87.8 & 87.5 \\
\hline
\end{tabular}

a The calculation of $w$ is based on a molecular weight of 13,950 for porcine PLA $\mathbf{P A}_{2}, 13,750$ for bovine PLA,

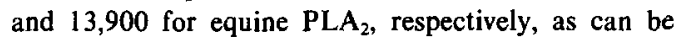
derived from the amino acid composition.

${ }^{b}$ See Refs. $(19,3,20)$.

fined maximum. The position of the second peak for $\mathrm{PLA}_{2}$ on the $\bar{Z}_{\mathrm{H}}$ axis is given by

$$
\begin{aligned}
\bar{Z}_{\mathrm{H}}=n_{\mathrm{LYS}}+n_{\mathrm{ARG}}-n_{\mathrm{COOH}} & \\
& +\left(1-\alpha_{\mathrm{NH}_{2}}\right)
\end{aligned}
$$

It is assumed that carboxyl and histidyl groups are fully dissociated, the single terminal amino group partly dissociated, and all other groups still fully protonated at the second maximum (for a more extensive description of differential curves see, e.g., Refs. $(6,7))$. To compare proton titration results with other experimental observations (e.g., ${ }^{1} \mathrm{H}$ NMR) we will express our results in apparent $\mathrm{p} K$ values, $\mathrm{p} K_{1 / 2}^{(i)}$ being the $\mathrm{pH}$ value with $\alpha_{i}=0.5$. For $\mathrm{p} K_{1 / 2}^{(i)}$ we can write the relation

$$
\mathrm{p} K_{\mathrm{i} / 2}^{(i)}=\mathrm{p} K_{\mathrm{int}}^{(i)}-0.868 w \bar{Z}_{\mathrm{H}}
$$

where $\bar{Z}_{\mathrm{H}}$ is the proton charge at that $\mathrm{pH}$ for which $\alpha_{i}=0.5$. For the calculation of the number of protons dissociated from the protein $\left(\bar{n}_{\mathrm{H}}\right)$ the relation is used

$$
\bar{n}_{\mathrm{H}}=\left(m_{\mathrm{t}}-m_{\mathrm{w}}\right) / m_{\mathrm{p}}
$$

where $m_{\mathrm{t}}$ is the total amount of added titrant (acid or base), $m_{\mathrm{w}}$ the part of $m_{\mathrm{t}}$ which does not interact with the protein, and $m_{\mathrm{p}}$ the total amount of protein. The value for $m_{\mathrm{w}}$ is calculated from the $\mathrm{pH}$ difference of the protein solution before and after addition of $m_{\mathrm{t}}$ moles of acid or base. The $\bar{n}_{\mathrm{H}}$ value can simply be converted to $\bar{Z}_{\mathrm{H}}$ when the $\mathrm{pH}$ of the isoionic solution is known. The partial amino acid composition and calculated electrostatic interaction factor $w(I=0.1 \mathrm{M})$ for the several studies proteins are given in $\mathrm{Ta}$ ble 1 .

\section{RESULTS AND DISCUSSION}

\section{Test and Calibration of Titration System}

When some small software changes are carried out, the titration program is also suitable for titer determinations. Figure 3 shows the titer determination of $\mathrm{NaOH}$ on oxalic acid. At $\mathrm{pH}$ values below 5.5 and above 9.5, a high point density is shown (an averaged point density of 200 points/pH unit). Just before and after the endpoints indicated by the two maxima in the differential curve, the density is lower ( 13 points $/ \mathrm{pH}$ unit) but still high enough for an exact endpoint calculation. The presence of two endpoints demonstrates for two titratable groups the effect of long-range electrostatic interactions during the course of titration.

Titrator mode 1/10 was used in all ex-

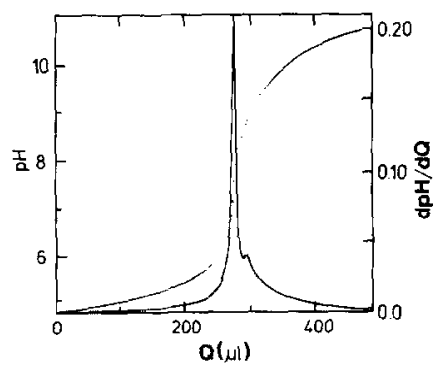

FIG. 3. Determination of the $\mathrm{NaOH}$ titer using 21.6 $\mathrm{mg}$ oxalic acid (Merck, pro analysis) in $100 \mathrm{mM} \mathrm{KCl}$ solution ( $5 \mathrm{ml}, \mathrm{CO}_{2}$ free). After addition of $5 \mathrm{ml} \mathrm{NaOH}$ the automated titration is started at pH 5, adding titrant with steps of $2 \mu \mathrm{l}$ to a total amount of $500 \mu \mathrm{l}$ in titrator mode $1 / 10$. . ., Normal titration curve $(\mathrm{pH}$ vs $\mu \mathrm{l})$; -, differential curve (dpH/d $Q$ vs $Q$ ). 


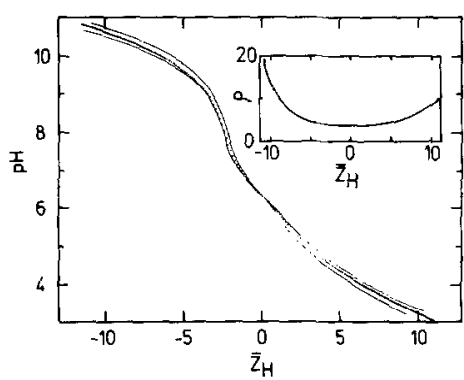

FIG. 4. Reproducibility of titration experiments. .. ., Normal titration curve (pH vs $\bar{Z}_{\mathrm{H}}$ ) of porcine $\mathrm{PLA}_{2}$, an average of 11 titration curves; - , lines indicating the maximum deviation from the average curve. Inset: point density $\rho$ vs $\bar{Z}_{\mathbf{H}}$, where $\rho$ is defined as the number of data points in intervals of $0.5 \bar{Z}_{\mathrm{H}}$ unit.

periments. Only one test experiment was performed in mode $1 / 1$ with a $5-\mathrm{ml}$ solution of $0.1 \mathrm{mM}$ porcine $\mathrm{PLA}_{2}$ and compared to an identical titration in mode $1 / 10$. The first titration showed a significantly lower signalto-noise ratio while initial and final $\mathrm{pH}$ values were the same. The faster addition of titrant is less accurate, especially when small amounts are added. According to the specifications given by the manufacturer, the inaccuracy is $\pm 0.5 \mu$ for mode $1 / 1$ and \pm 0.075 $\mu l$ for mode $1 / 10$. The reproducibility of the proton-titration experiments was tested on porcine $\mathrm{PLA}_{2}$. Figure 4 shows the titration curve for this enzyme averaged over $11 \mathrm{ex}$ periments. For the averaging procedure a software program based on a linear interpolation method was written. The porcine $\mathrm{PLA}_{2}$ titration curve shows a high point density over the whole $\mathrm{pH}$ range (inset Fig. 4).

The two solid lines in Fig. 4 represent boundary values for 11 titration curves with the IIP ( $\mathrm{pH} \mathrm{6.4)} \mathrm{as} \mathrm{reference} \mathrm{point.} \mathrm{It} \mathrm{ap-}$ peared that a high degree of reproducibility could be obtained ( $S D \pm 0.2$ proton) for double or triple experiments using the same stock solution of protein. Interexperiment comparisons give standard deviations of at most 0.5 proton.

\section{Proton Titrations of Phospholipases $A_{2}$}

General features of the titration behavior of phospholipases $\mathrm{A}_{2}$ (as earlier described by
Janssen et al. (8) for porcine PLA $\mathrm{A}_{2}$ ) are most clearly demonstrated by differential titration curves (see Fig. 5). A well-defined sharp maximum ( $\max 2$ at $\bar{Z}_{\mathrm{H}}$ from -1 to -2.5 ) can be observed and defined as the titration endpoint of all titratable histidines and carboxylates and as the starting point for lysines and tyrosines. The position of this maximum at $\mathrm{pH} 8$ to 9 appeared to be an excellent help in group counting (see Eq. [4]) while it is very sensitive to $\mathrm{p} K$ changes in this region. Another maximum ( $\max 1$ for $\bar{Z}_{\mathrm{H}}$ from +1 to +3 ) is less well defined ( $\mathrm{pH} \mathrm{5.5-6.5)} \mathrm{and}$ appeared to be less helpful in quantitative determinations.

Figure 5 shows the normal and differential titration curves for porcine, bovine, and equine $\mathrm{PLA}_{2}$, respectively, taking the IIP as a reference point. The differences in IIP (Table 2) clearly reflect the differences in amino acid composition (Table 1). These differences are also indicated by the positions of $\max 2$ on the $\bar{Z}_{\mathrm{H}}$ axis in the differential titration curves (Fig. 5). The increasing number of histidine residues in the series (horse 1, ox 2, pig 3 ) gives rise to a shift of

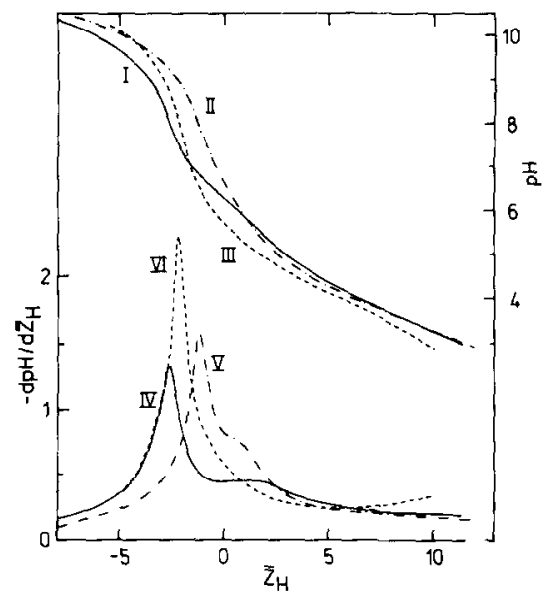

Fig. 5. Normal and differential titration curves for native $\mathrm{PLA}_{2} \mathrm{~S}$ at $I=0.1 \mathrm{M}$ and $25^{\circ} \mathrm{C}$. I and $\mathrm{IV}$, normal and differential curve for porcine PLA $A_{2}$, respectively; II and $V$, for bovine PLA $;$; III and VI, for equine PLA $A_{2}$. The reference point $\left(\bar{Z}_{\mathrm{H}}=0\right)$ is the $\mathrm{pH}$ of the isoionic solution (Table 2). No point density is shown, but the curves are continuous lines drawn through the data points. 
TABLE 2

Titration Data at an Ionic Strenath of 0.1 m for Porcine, Bovine, and Equine Phospholipase $\mathrm{A}_{2}$

\begin{tabular}{|c|c|c|c|c|c|c|c|c|}
\hline \multirow[b]{2}{*}{ Enzyme } & \multicolumn{4}{|c|}{ Parameters of max 2} & \multicolumn{2}{|c|}{$\begin{array}{l}\text { Aspartic and glutamic } \\
\text { acids }\end{array}$} & \multicolumn{2}{|c|}{ Histidines } \\
\hline & IIP & $\mathrm{pH}$ & $\bar{Z}_{\mathrm{H}}$ & $\begin{array}{l}\mathrm{dpH} / \\
\mathrm{d} \bar{Z}_{\mathrm{H}}\end{array}$ & $\overrightarrow{\mathrm{p} K}_{1 / 2}$ & $\overline{\mathrm{pK}}_{\mathrm{int}}$ & $\overline{\mathrm{p}}_{1 / 2}$ & $\overline{\mathrm{p}}_{\mathrm{int}}$ \\
\hline Pig & 6.4 & $8.05 \pm 0.05$ & $-2.2 \pm 0.05$ & $1.4 \pm 0.2$ & $3.53 \pm 0.03$ & $4.19 \pm 0.04$ & $6.6 \pm 0.1(6.5)^{a}$ & $6.6 \pm 0.1$ \\
\hline Ox & 6.6 & $7.85 \pm 0.05$ & $-1.07 \pm 0.03$ & $1.7 \pm 0.2$ & $3.63 \pm 0.03$ & $4.26 \pm 0.04$ & $6.6 \pm 0.1(6.5)$ & $6.6 \pm 0.1$ \\
\hline Horse & 5.7 & $7.82 \pm 0.05$ & $-2.07 \pm 0.03$ & $2.3 \pm 0.3$ & $3.93 \pm 0.05$ & $4.31 \pm 0.06$ & $6.6 \pm 0.2(6.4)$ & $6.5 \pm 0.1$ \\
\hline
\end{tabular}

${ }^{a}$ The values between parentheses are determined by ${ }^{1} \mathrm{H}$ NMR measurements (10); the 'H NMR values for porcine PLA $A_{2}$ are given here as the average of the $\mathrm{p}_{\mathrm{l} / 2}$ values of $\mathrm{His}^{17}$ and $\mathrm{His}^{15}$ (the value for $\mathrm{His}^{48}$ could not be determined).

the poorly resolved max 1 to lower $\mathrm{pH}$ values, while the height of that maximum is reduced. This behavior can be deduced from Eq. [3].

In sequence work accurate determination of the number of carboxylates in proteins can be subject to error. The position of $\max$ 2 on the $\bar{Z}_{\mathbf{H}}$ axis in $\mathrm{pH}$ titration curves as in Fig. 5 provides an excellent check on the number of carboxylates when the number of histidines, lysines, arginines, and terminal amino groups is known. One complication may be that the $\alpha-\mathrm{NH}_{2}$ amino group titrates over the region where $\max 2$ is located. For pancreatic $\mathrm{PLA}_{2} \mathrm{~s}$ of pig, ox, and horse the $\mathrm{p} K_{1 / 2}$ values of the $\alpha-\mathrm{NH}_{2}$ groups are known, being $8.4,8.9$, and 8.8 , respectively $(8,9)$. These $\mathrm{p} K_{1 / 2}$ values are high enough to expect little effect on the determination of the endpoint for carboxylate deprotonation (around

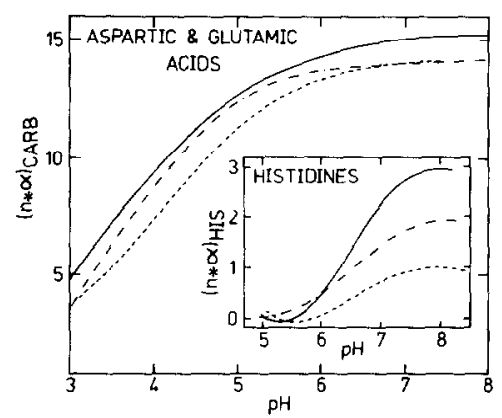

FIG. 6. Titration curves of carboxylates and histidines (inset) of native PLA $A_{2}--$, Porcine PLA $A_{2}-\cdots \cdot-\cdot$, bovine PLA ${ }_{2}$; - - , equine PLA
$\mathrm{pH} 7$ ). Indeed, calculation of the position of $\max 2$ on the $\bar{Z}_{\mathrm{H}}$ axis $\left(Z_{\mathrm{II}}\right)$ in the differential curves for porcine and bovine $\mathrm{PLA}_{2} \mathrm{~s}$ using Eq. [4] and the reported amino acid compositions (Table 1) leads to exactly the same values as experimentally found, -2.2 and -1.07 , respectively. These numbers deviate from integer values, due to the effect of the titration of the $\alpha-\mathrm{NH}_{2}$ groups.

However, the theoretical value for equine $\mathrm{PLA}_{2}$ appeared to be -3.07 , i.e., 1 proton lower than the experimental value. This is a clear indication that the number of carboxylates taken from the reported amino acid composition is most probably incorrect. It is very likely that a reported acidic residue is actually an amide. A candidate is $\mathrm{Asp}^{86}$ which should be $\operatorname{Asn}^{86}$ (H. M. Verheij, personal communication).

The height of max 2 reflects the number and dissociation degree of groups titrating at that $\mathrm{pH}$, being largest for porcine $\mathrm{PLA}_{2}$ and least for equine $\mathrm{PLA}_{2}$ (see Eq. [3]). Figure 6 shows the titration curves of the aspartic and glutamic acids of the three enzymes. For these we applied Eq. [2] using values from Table 1 for $Z_{\max }$ and for the number of histidines. The $\mathrm{p} K_{1 / 2}$ values for the histidines were taken from Aguiar et al. (10), and the $\mathrm{p} K_{1 / 2}$ values for the $\alpha-\mathrm{NH}_{2}$ from Jansen et al. (9). The $\mathrm{p} K_{\mathrm{int}}$ of the Cterminal $\mathrm{COOH}$ group was set to 3.6 , the $\mathrm{p} K_{\text {int }}$ of the lysines to 10.3 , and of the tyrosines to $9.6(5)$. The results shown in Fig. 
6 clearly indicate that the number of glutamic and aspartic acids titrating in the horse enzyme is 14 , not 15 as shown in Table 1.

For the carboxyl side chains an apparent $\mathrm{p} K$ value can be calculated representing the average value for the glutamic and aspartic acids. Table 2 shows that this value is far below the values reported for aspartic groups ( $\mathrm{p} K 4.08$ ) or glutamic groups $(\mathrm{p} K 4.50)$ in model compounds (11). This demonstrates that the carboxyl groups are titrating in a strongly positive protein molecule as is clear from Fig. 5. Low $\mathrm{p} K_{1 / 2}$ values for carboxyl groups were reported earlier for porcine pancreatic phospholipase $A_{2}$ (12), lysozyme (13-15), ribonuclease (16), deoxy- and oxyhemoglobin A (17), sperm whale ferrimyoglobin (18), and many other studied proteins. The titration curves of the histidines are shown in the inset of Fig. 6 using the same boundary conditions as for the carboxyl groups only replacing the $\mathrm{p} K_{\text {int }}$ and number of the histidines by the corresponding values for the acidic groups. The $\mathrm{p} K_{\text {int }}$ for the latter was calculated from Eq. [1] plotting $\mathrm{pH}-\log (\alpha / 1-\alpha)$ vs $\bar{Z}_{\mathrm{H}}$ where $\alpha$ represents the degree of dissociation of the carboxyl groups. The $\alpha$ was calculated as $\alpha=\left(Z_{\max }-n_{\mathrm{His}} \alpha_{\mathrm{His}}-\bar{Z}_{\mathrm{H}}\right) / n_{\mathrm{COOH}}$. The $\mathrm{p} K_{\text {int }}$ was derived from the intercept at the point $\bar{Z}_{\mathrm{H}}=0.0$. This value can also be deduced from Eq. [5], resulting in the values given in Table 2.

Table 2 gives the average apparent and intrinsic $\mathrm{p} K$ values for the histidines, which are in excellent agreement with the ${ }^{1} \mathrm{H}$ NMR values of Aguiar et al. (10) and with the proton-titration results of Janssen et al. (8) for the porcine enzyme.

The high reproducibility and accuracy of the above-mentioned automated experiments and the agreement between experimental and theoretical or literature values give us a strong support to carry out more quantitative calculations on individual $\mathrm{p} K_{\text {int }}$ values. Therefore, we extended our measurements to study the zymogens and several derivatives of the above mentioned enzymes. These results will be published elsewhere.

\section{REFERENCES}

1. Nieuwenhuizen, W., Kunze, H., and de Haas, G. H. (1974) in Methods in Enzymology (Fleischer, S., and Packer, L., eds.), Vol. 32B, pp. 147-154, Academic Press, New York.

2. Evenberg, A., Meyer, H., Verheij, H. M., and de Haas, G. H. (1977) Biochim. Biophys. Acta 491, 265-274.

3. Fleer, E. A. M., Verheij, H. M., and de Haas, G. H. (1978) Eur. J. Biochem. 82, 261-270.

4. Linderstrøm-Lang, K. (1924) C. R. Trav. Lab. Carlsberg 15, 1-29.

5. Tanford, C. (1962) Adv. Prot. Chem. 17, 96-165.

6. de Bruin, S. H., and van Os, G. A. J. (1968) Recueil 87, 861-872.

7. Janssen, L. H. M., de Bruin, S. H., and van Os, G. A. J. (1970) Biochim. Biophys. Acta 221, 214-227.

8. Janssen, L. H. M., de Bruin, S. H., and de Haas, G. H. (1972) Eur. J. Biochem. 28, 156-160.

9. Jansen, E. H. J. M., van Scharrenburg, G. J. M., Slotboom, A. J., de Haas, G. H., and Kaptein, R. (1979) J. Amer. Chem. Soc. 101, 7397-7399.

10. Aguiar, A., de Haas, G. H., Jansen, E. H. J. M., Slotboom, A. J., and Williams, R. J. P. (1979) Eur. J. Biochem. 100, 511-518.

11. Nozaki, Y., and Tanford, C. (1967) J. Biol. Chem. 242, 4731-3735.

12. Abita, J., Lazdunski, M., Bonsen, P. P. M., Pieterson, W. A., and de Haas, G. H. (1972) Eur. J. Biochem. 30, 37-47.

13. Tanford, C., and Roxby, R. (1972) Biochemistry 11, 2192-2198.

14. Kuramitsu, S., and Hamaguchi, K. (1980) J. Biochem. 87, 1215-1219.

15. Roxby, R., and Tanford, C. (1971) Biochemistry 10, 3348-3357.

16. Nozaki, A., and Tanford, C. (1967) J. Amer. Chem. Soc. 89, 742-749.

17. Matthew, J. B., Hanania, G. I. H., and Gurd, F. R. N. (1979) J. Amer. Chem. Soc. 18, 19191927.

18. Shire, S. J., and Hanania, G. I. H. (1974) Biochemistry 13, 2967-2974.

19. Puyk, W. C., Verheij, H. M., and de Haas, G. H. (1977) Biochim. Biophys. Acta 492, 254-259.

20. Evenberg, A., Meyer, H., Gaastra, W., Verheij, H. M., and de Haas, G. H. (1977) J. Biol. Chem. 252, 1189-1196. 